\title{
CONCRETOS PRODUZIDOS COM AGREGADO E ADIÇĀO MINERAL DE ESCÓRIA DE ACIARIA
}

\section{COSTA, LAIS CRISTINA}

Doutoranda em Engenharia Civil Universidade Federal de Ouro Preto Minas Gerais; Brasil

lais.cristina.costa@gmail.com

ELÓI, FERNANDA

Mestranda em Engenharia Civil Universidade Federal de Ouro Preto Minas Gerais; Brasil fernandaeloi94@gmail.com

\section{BATISTA, JUNIO}

Técnico em Edificações Universidade Federal de Ouro Preto Minas Gerais; Brasil juniobatista07@gmail.com

\author{
FERREIRA, LARRISA CAROLINE \\ Graduanda em Engenharia Civil \\ Universidade Federal de Ouro Preto \\ Minas Gerais; Brasil \\ larissa.caroline@aluno.ufop.edu.br \\ NOGUEIRA, MARCELA \\ Mestranda em Engenharia Civil \\ Universidade Federal de Ouro Preto \\ Minas Gerais; Brasil \\ marcela.nogueira@aluno.ufop.edu.br \\ PEIXOTO, RICARDO ANDRÉ \\ Engenheiro Civil, D.Sc \\ Universidade Federal de Ouro Preto \\ Minas Gerais; Brasil \\ fiorotti.ricardo@gmail.com
}

\section{RESUMO}

O concreto é o segundo produto mais consumido no mundo possuindo elevado impacto ambiental, devido a significativa emissão de $\mathrm{CO}_{2}$ na produção do cimento e as atividades extrativas para obtenção de agregados. Por isso, crescem os estudos de incorporação de resíduos industriais em matrizes cimentícias. Destaca-se a escória de aciaria, resíduo da indústria siderúrgica, majoritariamente destinada a depósitos. O objetivo desse estudo é avaliar concretos produzidos inteiramente com agregados de escória de aciaria e com adição mineral de escória de aciaria, denominado powder LD. Para comparação, foram produzidos concretos com agregado convencional, adição mineral comercial e sem nenhuma adição mineral. Os concretos produzidos completamente com agregado de escória de aciaria apresentaram maiores resistências à compressão, a maior resistência do agregado e forma favorável cria uma matriz mais competente mecanicamente. Além disso, a utilização do powder LD melhorou a propriedade mecânica do concreto, tendo comportamento similar a adição mineral comercial, devido a uma provável ação cimentante ou efeito nucleador. De forma geral, todos os concretos produzidos foram classificados como de boa qualidade, quanto a velocidade de pulso ultrassônico, isso indica que a estrutura de poros formada por eles foi favorável. Assim, os resultados demonstram que a escória de aciaria melhora o desempenho das matrizes, indicando a viabilidade técnica da sua utilização.

Palavras-chave: Escória de aciaria; Sustentabilidade; Concreto; Adição mineral

\begin{abstract}
Concrete is the second most consumed product in the world with a high environmental impact due to the significant $\mathrm{CO}_{2}$ emission in cement production and extractive activities to obtain aggregates. Therefore, it is growing the studies to incorporate of industrial residues in cementitious matrices. Stands-out the steel slag usually destined to landfills. The aim of this study is to evaluate concretes produced entirely with steel slag aggregates and with mineral addition of steel slag, called powder LD. For comparison, concretes with conventional aggregate, commercial mineral addition and no mineral addition were produced. The concretes produced completely with steel slag aggregate presented higher compressive strengths, the higher mechanical resistance of the aggregate combined with it morphology create a matrix better mechanically. In addition, the use of LD powder improved the mechanical property of concrete with a similar behavior to the commercial mineral addition, probably due to a cementitious action or nucleation. In general, all the concretes produced were classified as of good quality, regarding ultrasonic pulse speed, showing that the porous system is favorable. Thus, the results demonstrate that steelmaking slag improves the performance of the matrices, indicating the technical feasibility of its use.
\end{abstract}




\section{INTRODUÇÃO}

O concreto é o segundo produto mais consumido no mundo, perdendo apenas para a água (um dos seus componentes), para possibilitar a sua produção é necessário grande extração de recursos naturais e gera elevada emissão de $\mathrm{CO}_{2}$. $\mathrm{O}$ componente do concreto com maior impacto ambiental é o cimento Portland, que além de demandar recursos naturais ainda possui notória emissão de $\mathrm{CO}_{2}$. Apesar do inegável impacto da indústria cimenteira, não se pode neglicenciar que cerca de 70-80\% do volume do concreto compoem se de agregados (MEHTA e MONTEIRO, 2013). A fabricação desse material leva a mudanças no leito de rios, poluição de cursos d'água e mudanças na fauna e flora (ALEXANDER e MINDNESS, 2005; PADMALAL, MAYA, et al., 2008). O mundo consumiu 45 bilhões de toneladas de agregados em 2015, no mesmo período foi requerido 10\% desse montante de cimento Portland (ANEPAC, 2015).

Por esses motivos, é crescente a busca por soluções viáveis economica, ambiental e socialmente para a grande utilização de cimento Portland e agregados. Nos últimos anos, diversos estudos se destacaram ao incorporar resíduos industriais da siderurgia e mineração como material cimentício suplementar (DEFÁVERI, MENDES, et al., 2019; SILVA, C., et al., 2018) e agregados (FRANCO , MENDES , et al., 2019; SILVA, SOUZA, et al., 2016; FONTES, MENDES, et al., 2016; SANT'ANA FILHO, SILVA, et al., 2017). Destaca-se aqueles trabalhos que utilizam escória de aciaria, um resíduo da indústria siderúrgica que é destinado marjoritariamente a fins pouco nobres como depósitos e tem uma geração de 5,8 milhões de toneladas por ano apenas no Brasil (IABR, 2018).

Dentre os diversos estudos sobre a escória de aciaria, ressaltam-se os que avaliam sua utilização na forma de adição mineral, analisando o seu potencial como material cimentante suplementar (WANG, YANG e YAN, 2013; SHI, CHEN, et al., 2017; ROSLAN, ISMAIL, et al., 2016). Observa-se que a incorporação de finos de escória de aciaria contribui com o refino dos poros possibilitando uma matriz mais durável e resistente (CARVALHO, MELO, et al., 2019), além de aumentar a ecoeficiencia das matrizes (CARVALHO, FONTES, et al., 2020). Como agregado, a escória de aciaria apresenta propriedades mecânicas e físicas superiores e/ou equivalentes aos convencionais, (MONOSI, RUELLO e SANI, 2016; SAN-JOSÉ, VEGAS, et al., 2014; BISKRI, ACHOURA, et al., 2017; SOUZA, 2015). No entanto, destaca-se que nesses estudos é realizado substituição total de agregados graúdos por escória de aciaria e parcial de agregados miúdos por areia de escória de aciaria.

Assim, apesar dessa larga investigação das possíveis utilizações para a escória de aciaria, carece na literatura de trabalhos que avaliem a fabricação de concretos apenas com agregados de escória de aciaria combinado a incorporação de adições minerais produzidas a partir do mesmo resíduo. Assim, o presente estudo buscou fabricar matrizes com elevado teor de aproveitamento de escória de aciaria como agregado (miúdo e graúdo) e adição mineral avaliando o seu desempenho mecânico, comparando com matrizes produzidas com agregados convencionais e adições comerciais.

\section{MATERIAIS E MÉTODOS}

\subsection{Materiais}

Para produção dos concretos, foi utilizado cimento Portland CP IV RS devido a substituição parcial de clínquer (15-50\%) por material pozolânico (ABNT, 2018). Sendo assim um cimento com menor impacto ambiental. A massa específica do cimento é $3,01 \mathrm{~g} / \mathrm{cm}^{3}$.

Os agregados de escória de aciaria foram produzidos a partir do resíduo proveniente de uma usina siderúrgica em Minas Gerais, que funciona de acordo com a metodologia integrada Linz-Donawitz. Esse material foi estabilizado, para hidratação dos óxidos livres, em pátios abertos por um período de quatro anos. Ao ser recebida, toda a escória de aciaria passou por processo de separação magnética via seco em rolo magnético (Inbras CC $\varnothing 12$ x 12, intensidade 950 Gauss). $\mathrm{O}$ agregado graúdo de escória de aciaria foi produzido a partir de peneiramento a fim de se adequar aos limites da NBR 7211 (ABNT, 2009). Com relação ao agregado miúdo de escória de aciaria, o resíduo bruto foi moído em britador de mandíbula (Retsch BB 100) com posterior separação gravimétrica a fim de adequar as especificações da NBR 7211 (ABNT, 2009).

A fim de produzir concretos de referência com finalidade comparativa foi utilizado britas de gnaisse, extraídas de Belo Horizonte (MG), e areia quartzosa de rio, proveniente de Ponte Nova (MG). Para que os concretos fossem fisicamente iguais, permitindo avaliar isoladamente os efeitos da morfologia e composição química da escória de aciaria, os agregados convencionais passaram pelo processo de separação gravimétrica obtendo a mesma curva granulométrica dos agregados de escória de aciaria. A Figura 1 mostra a curva granulométrica dos agregados. 


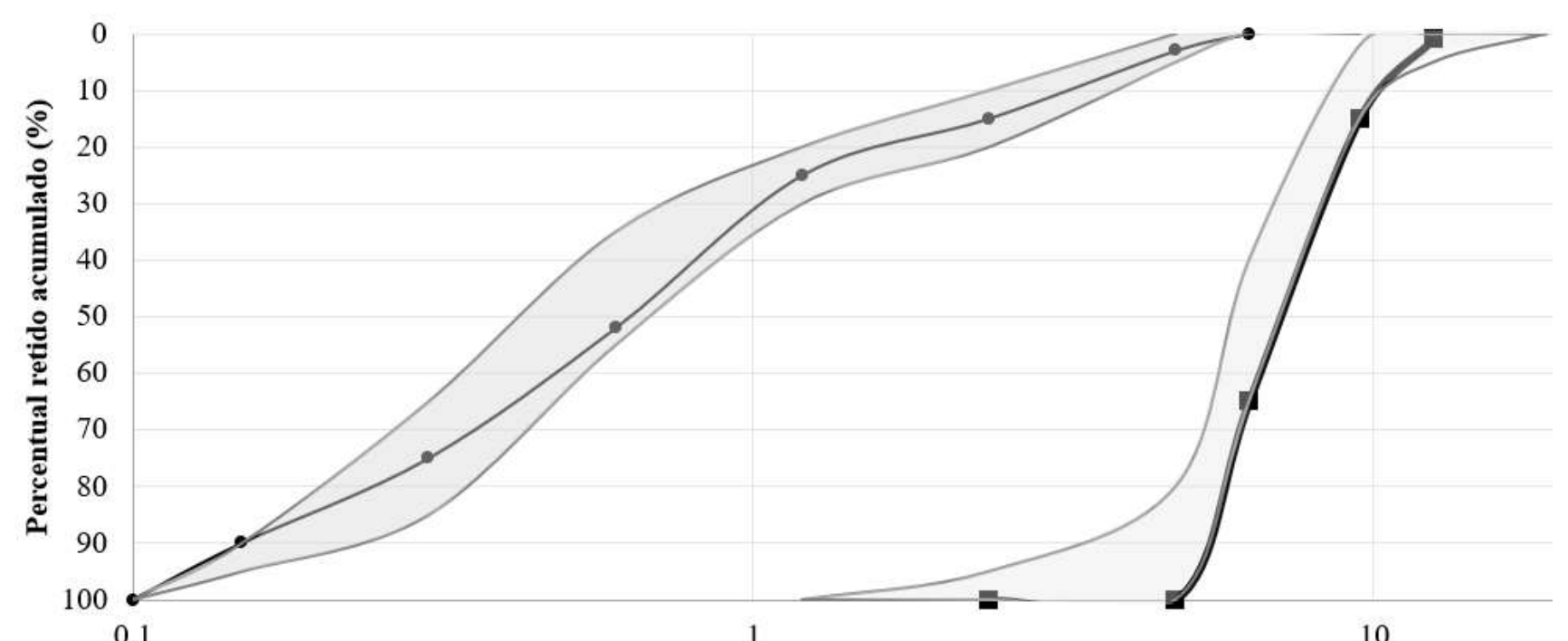

0.1

1

10

\section{Abertura da malha (mm) \\ Agregado Miúdo \\ Agregado Graúdo}

Figura 1 - Curva granulométrica dos agregados

A completa caracterização física dos agregados (convencionais e de escória) é apresentada na Tabela 1, assim como as respectivas normatizações de ensaio.

Tabela 1 - Caracterização dos agregados

\begin{tabular}{c|c|c|c|c|c}
\hline & \multicolumn{2}{|c|}{ Agregado miúdos } & \multicolumn{2}{c|}{ Agregado graúdo } & \multirow{2}{*}{ Normatização do ensaio } \\
\cline { 2 - 5 } & $\begin{array}{c}\text { Escória de } \\
\text { aciaria }\end{array}$ & Referência & $\begin{array}{c}\text { Escória de } \\
\text { aciaria }\end{array}$ & Referência & NBR 9776 (ABNT, 1986)/ \\
\hline $\begin{array}{c}\text { Massa específica } \\
\left(\mathrm{g} / \mathrm{cm}^{3}\right)\end{array}$ & 3,74 & 2,68 & 3,58 & 2,61 & $\begin{array}{c}\text { NBr } \\
\text { NBR NM 53 (ABNT, 2009) }\end{array}$ \\
\hline $\begin{array}{c}\text { Massa unitária } \\
\left(\mathrm{g} / \mathrm{cm}^{3}\right)\end{array}$ & 2,22 & 1,63 & 1,77 & 1,44 & NBR NM 45 (ABNT, 2006) \\
\hline $\begin{array}{c}\text { Material } \\
\text { pulverulento }(\%)\end{array}$ & 8,06 & 6,26 & 1,93 & 0,81 & NBR NM 46 (ABNT, 2003) \\
\hline $\begin{array}{c}\text { Resistência ao } \\
\text { esmagamento }(\%)\end{array}$ & \multicolumn{2}{|c|}{-} & $89,41$. & 82,90 & NBR 9938 (ABNT, 2013) \\
\hline Índice de forma & \multicolumn{2}{|c|}{-} & 1,47 & 1,81 & NBR 7809 (ABNT, 2019) \\
\hline
\end{tabular}

A adição mineral de escória de aciaria, doravante denominada powder LD, foi produzida a partir do agregado miúdo de escória de aciaria. Esse material foi passado na peneira de 4,8mm e então moído em moinho de bolas de baixa eficiência (Marconi MA500) por 3 horas a 200 RPM. Posteriormente foi cominuído em moinho planetário de alta eficiência (Retsch PM100) por 15 minutos a 400 RPM. Como referência ao powder LD foi empregada a sílica ativa, uma pozolana que é uma das adições minerais mais vendidas no Brasil.

Para fabricação dos concretos, também foi utilizada água potável proveniente do sistema de abastecimento público de Ouro Preto, e aditivo superplastificante de terceira geração (eter policarboxilico, MC Bauchemie Powerflow 1180), que permite melhora da trabalhabilidade sem aumento do fator água/cimento.

\subsection{Métodos}

\subsubsection{Caracterização das adições minerais}

Adições minerais (sílica ativa e powder LD) foram caracterizadas de acordo com suas propriedades físicas e composição química. As características físicas avaliadas nas adições minerais foram: massa específica (NBR 16605:2017) e a granulometria. A distribuição granulométrica foi obtida através da técnica de difração de laser (Bettersize 2000) usando 
água destilada como meio dispersor. Para o cimento CPIV, a granulometria foi obtida com a mesma metodologia, usando álcool isopropílico como meio dispersor.

A composição química dos materiais utilizados como adição foi obtida por fluorescência de raio-X (PANalytical Epsilon3x). Para preparação das amostras, as adições minerais foram submetidas a separação gravimétrica utilizando os materiais passantes na peneira de abertura $75 \mu \mathrm{m}$. Além disso, as adições foram submetidas a uma avaliação mineralógica através da técnica de difração de Raios-X (Bruker D2 Phaser) com tubo de CuKa, tensão de 45kV, 40mA, velocidade de giro de $8 \mathrm{rpm}, 2 \theta$ variando de $6-80^{\circ}$ com passo de $0,02^{\circ}$ e tempo de 1 segundo por passo. A fim de fazer uma análise quantitativa, foi adicionado $10 \%$ de fluorita em massa como padrão interno. Para identificação das fases mineralógicas e aplicação do método de refinamento de Rietveld foi utilizado o software X'Pert High Score Plus com a Crystallography Open Database (COD) de 2013.

\subsubsection{Produção e caracterização dos concretos}

Os concretos foram dosados a partir da metodologia do Instituto de Pesquisa Tecnológica (IPT) com teor fixo de 59\% de argamassa, consumo de cimento fixo de $310 \mathrm{~kg} / \mathrm{m}^{3}$ e fator água/aglomerante (a/agl) de 0,62. As adições minerais (sílica ativa e powder LD) foram adicionadas em volume seguindo a sugestão máxima de incorporação do fabricante da sílica ativa, $8 \%$. Para garantir concretos com mesma funcionalidade, foi definido um slump de $90 \mathrm{~mm}$ com tolerância de $10 \mathrm{~mm}$ de acordo com a NBR 7212 (ABNT, 2012). O teor de aditivos foi dosado de forma empírica a fim de se obter a trabalhabilidade desejada. Assim, os traços foram compostos em blocos casualizados de acordo com o tipo de agregado. Receberam identificação no qual a o código inicial corresponde ao tipo de agregado (REF: referência e ELD: escória de aciaria), seguida da adição, sendo: sem adição (00), sílica ativa (SA) e powder LD (PLD). A Tabela 2 apresenta a composição dos traços de concreto produzidos.

Tabela 2 - Traços de concreto com relação ao consumo de cimento

\begin{tabular}{c|c|c|c|c|c|c}
\hline Código & Cimento $\left(\mathbf{k g} / \mathbf{m}^{\mathbf{3}}\right)$ & $\mathbf{A . ~ M i u ́ d o ~}\left(\mathbf{k g} / \mathbf{m}^{\mathbf{3}}\right)$ & $\mathbf{A . ~ G r a u ́ d o ~}\left(\mathbf{k g} / \mathbf{m}^{\mathbf{3}}\right)$ & Água $\left(\mathbf{k g} / \mathbf{m}^{\mathbf{3}}\right)$ & Adição $\left(\mathbf{k g} / \mathbf{m}^{\mathbf{3}}\right)$ & $\mathbf{A d i t i v o ~}(\boldsymbol{\%})$ \\
\hline REF-00 & 310 & 936,65 & 866,31 & 190,65 & 0 & 0,4 \\
\hline REF-SA & 310 & 930,06 & 861,74 & 201,82 & 15,51 & 0,90 \\
\hline REF-PLD & 310 & 908,85 & 846,99 & 213,46 & 34,29 & 0,35 \\
\hline ELD-00 & 310 & 1376,34 & 1171,86 & 190,65 & 0 & 0,58 \\
\hline ELD-SA & 310 & 1361,16 & 1161,31 & 201,82 & 15,51 & 0,70 \\
\hline ELD-PLD & 310 & 1330,80 & 1140,21 & 213,46 & 34,29 & 0,30 \\
\hline
\end{tabular}

Os concretos foram produzidos em uma betoneira de 120 L. A fim de obter melhor dispersão dos finos das adições minerais, as mesmas foram diluídas na água utilizada juntamente com o aditivo. A mistura foi realizada na seguinte ordem: agregado graúdo, cimento, agregado miúdo, sendo adicionado um terço da água em cada incorporação de novo componente. Após a inserção da agregado graúdo e do cimento foi procedido com uma mistura por 30 segundos, após a incorporação do agregado miúdo o conjunto foi homogeneizado por 5 minutos. A seguir foram moldados corpos de prova de $\varnothing 5 \times 10 \mathrm{~cm}$ adensados em duas camadas com 20 golpes por camada na mesa fluxo. Todo o processo de produção do concreto e moldagem dos corpos de prova tinha tempo máximo de duração de 1 hora para evitar possíveis mudanças na reologia da mistura devido ao processo de enrijecimento. Os corpos de prova foram curados em câmara úmida $\left(24^{\circ} \mathrm{C}\right.$, 95\% de umidade relativa) até a idade de teste.

Todos os traços produzidos foram caracterizados quanto as suas propriedades mecânicas e física, que são descritos na Tabela 3. Nos ensaios de caracterização mecânica foi utilizado prensa hidráulica universal servo-controlada (EMIC DL 20000) com velocidade de $0,3 \mathrm{MPa} / \mathrm{s}$ e célula de carga de $200 \mathrm{kN}$. Para o ensaio de velocidade de pulso ultrassônico (VPU) foi empregado o equipamento da marca Proceq realizando medições diretas com pulso ultrassônico de $54 \mathrm{~Hz}$. 
Tabela 3 - Ensaios e respectivos protocolos de caracterização dos concretos

\begin{tabular}{c|c|c|c}
\hline Ensaio & $\begin{array}{c}\text { Número de } \\
\text { Repetições por traço }\end{array}$ & Idade & Normatização \\
\hline Massa específica & \multirow{2}{*}{28 dias } & $\begin{array}{c}\text { NBR 9778:2005 } \\
\text { (ABNT, 2005) }\end{array}$ \\
\cline { 1 - 1 } Absorção de água por imersão & 3 & \multirow{3}{*}{42 dias } & NBR 5739:2018 (ABNT, 2018) \\
\cline { 1 - 1 } Resistência à compressão & 4 & NBR 7222:2011 (ABNT, 2011) \\
\hline Resistência à tração diametral & 4 & NBR 8802:2013 (ABNT, 2013) \\
\hline Velocidade Pulso Ultrassônico (VPU) & 4 & &
\end{tabular}

\section{RESULTADOS}

\subsection{Caracterização das adições minerais}

A Figura 2 apresenta a granulometria dos materiais finos utilizados. Nota-se que o powder LD tem o menor diâmetro de partículas dentre os materiais analisados. O D90 do powder LD, sílica ativa e cimento é respectivamente: $39,59 \mu \mathrm{m} ; 59,52$ $\mu \mathrm{m}$ e 41,87 $\mu \mathrm{m}$. Assim, o powder LD é aproximadamente 33\% menor que a da sílica ativa. Destaca-se ainda que na sílica ativa são encontradas partículas de até $140 \mu \mathrm{m}$ e que o D50 do powder LD é 8,55 $\mu \mathrm{m}$.

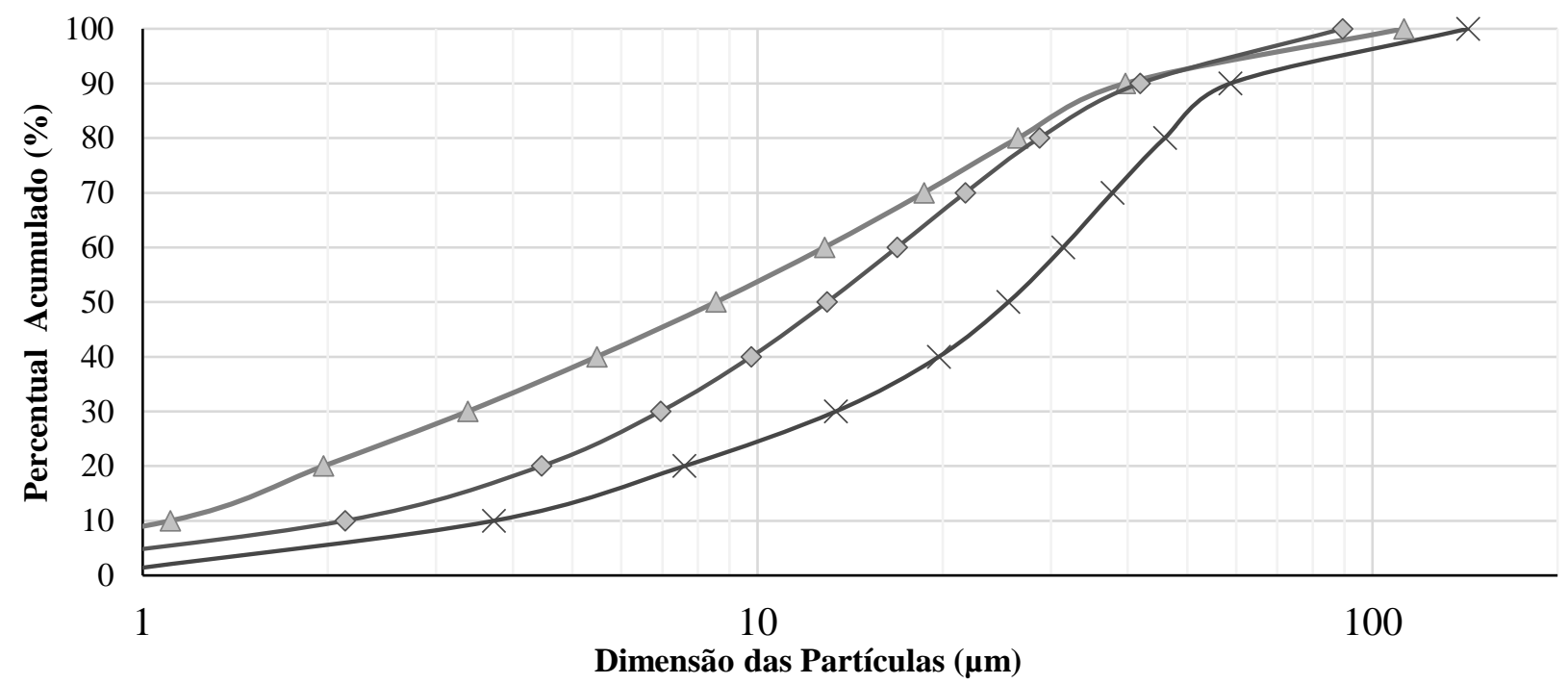

$\leftarrow$ Silica Ativa $\quad \smile$ Powder LD $\quad$ CP IV

Figura 2 - Granulometria das adições minerais e do cimento utilizado

O powder LD apresenta massa específica de $3,74 \mathrm{~g} / \mathrm{cm}^{3}$ enquanto a sílica ativa é $2,22 \mathrm{~g} / \mathrm{cm}^{3}$. O valor elevado para a adição de escória era esperado devido a sua composição com altos teores de metais como cálcio e ferro (SILVA, SOUZA, et al., 2016). A grande diferença entre esses materiais ressalta a importância das adições serem incorporadas em volume, garantindo que os poros da matriz sejam preenchidos com o mesmo volume de finos podendo isolar os efeitos derivados das caracterísitcas dos materiais. Com relação a composição química, a Tabela 4 mostra os seus resultados. Como esperado a sílica ativa é composta basicamente por óxido de sílicio, enquanto as fases de destaque no powder LD são óxidos de cálcio, ferro e silício.

Tabela 4 - Composição quimica das adições minerais

\begin{tabular}{c|c|c|c|c|c|c|c|c|c|c}
\hline & $\mathrm{SiO}_{2}$ & $\mathrm{Al}_{2} \mathrm{O}_{3}$ & $\mathrm{CaO}$ & $\mathrm{P}_{2} \mathrm{O}_{5}$ & $\mathrm{MgO}$ & $\mathrm{K}_{2} \mathrm{O}$ & $\mathrm{Fe}_{2} \mathrm{O}_{3}$ & $\mathrm{TiO}_{2}$ & $\mathrm{MnO}$ & Outros \\
\hline Sílica ativa & 96,8 & 0 & 1,1 & 0,4 & 0,4 & 0,7 & 0,2 & 0 & 0 & 0,4 \\
\hline Powder LD & 14,6 & 3,7 & 36,8 & 1,6 & 5,5 & 0 & 32,2 & 0,5 & 3,7 & 1,4 \\
\hline
\end{tabular}

A Tabela 5 apresenta a composição mineralógica do powder LD e da sílica ativa. Destaca-se inicialmente que a sílica ativa pode ser considerada basicamente amorfa apresentando apenas uma fase cristalina, o que auxilia no seu desempenho 
como pozolana e reatividade. Com relação a escória de aciaria, as principais fases encontradas foram calcita, wuestita, brownmillerita e larnita e apresenta um significativo teor de amorfo. Percebe-se que grande parte do magnésio e ferro observado na composição química encontra-se combinado a outros fases e não como óxidos livres. Esse resultado indica que a intemperização foi eficiente ao estabilizar esse material.

Tabela 5 - Composição mineralógica das adições minerais

\begin{tabular}{c|c}
\hline Powder LD & Sílica ativa \\
\hline Brownmillerita $-\mathrm{Ca}_{2}(\mathrm{Al}, \mathrm{Fe})_{2} \mathrm{O} 5-9,3 \%$ & Moissanite $-\mathrm{SiC}-1,2 \%$ \\
\hline Calcita $-\mathrm{CaCO}_{3}-12,0 \%$ & Amorfo $-98,8 \%$ \\
\hline Larnita $-\mathrm{Ca}_{2} \mathrm{SiO}_{4}-8,5 \%$ & \\
\hline $\mathrm{C}_{3} \mathrm{~S}$ monoclínico $-4,8 \%$ & \\
\hline Wuestita $-\mathrm{FeO}-11,0 \%$ & \\
\hline Periclásio $-\mathrm{MgO}-0,2 \%$ & \\
\hline Akermanita $-\mathrm{Ca}_{2} \mathrm{Mg}\left(\mathrm{Si}_{2} \mathrm{O}_{7}\right)-0,66 \%$ & \\
\hline $\mathrm{Cal}-\mathrm{CaO}-0,2 \%$ & \\
\hline Amorfo $-52,65 \%$ & \\
\hline
\end{tabular}

\subsection{Caracterização do concreto}

A Tabela 6 apresenta os resultados de massa específica e absorção de água dos concretos produzidos. Nota-se inicialmente que a incorporação de adições minerais não produziu alterações significativas no valor da massa específica do concreto. Como esperado, observa-se que a utilização de agregados de escória de aciaria aumentou cerca de $27 \%$ a massa específica do concreto. No entanto, segundo NBR 8953 (ABNT, 2015) todos os concretos são classificados como normais, podendo ser utilizados em colunas, vigas e lajes. Com relação a absorção de água, percebe-se que a incorporação de adições minerais possibilitaram a redução desse parâmetro. Para ambos os tipos de agregado, as menores absorções de água são obtidas para aqueles concretos com incorporação de sílica ativa, seguidos pelos com powder LD. A maior eficiência da sílica ativa em reduzir os poros permeáveis do concreto pode ser ocasionada pela sua maior reativadade devido ao alto teor de amorfo observado.

Tabela 6 - Massa específica e absorção de água dos concretos

\begin{tabular}{c|c|c|c|c|c|c}
\hline \multirow{2}{*}{} & \multicolumn{3}{|c}{ REF } & \multicolumn{3}{c}{ ELD } \\
\cline { 2 - 7 } & 00 & SA & PLD & 00 & SA & PLD \\
\hline Absorção de Água por Imersão & $7.58 \%$ & $5.68 \%$ & $6.34 \%$ & $5.93 \%$ & $4.92 \%$ & $5.22 \%$ \\
\hline Massa Específica & $2.1 \mathrm{~g} / \mathrm{cm}^{3}$ & $2.2 \mathrm{~g} / \mathrm{cm}^{3}$ & $2.2 \mathrm{~g} / \mathrm{cm}^{3}$ & $2.8 \mathrm{~g} / \mathrm{cm}^{3}$ & $2.8 \mathrm{~g} / \mathrm{cm}^{3}$ & $2.8 \mathrm{~g} / \mathrm{cm}^{3}$ \\
\hline
\end{tabular}

A Figura 3 apresenta os resultados de resistências e velocidade de pulso ultrassônico. Observa-se inicialmente que todos os resultados estão alinhados, revelando uma tendência onde os concretos com agregado escória se apresentam como melhores propriedades mecânicas comparado aos de agregado convencional. Com relação as adições minerais, nota-se que a sílica ativa melhora as propriedades do concreto. 


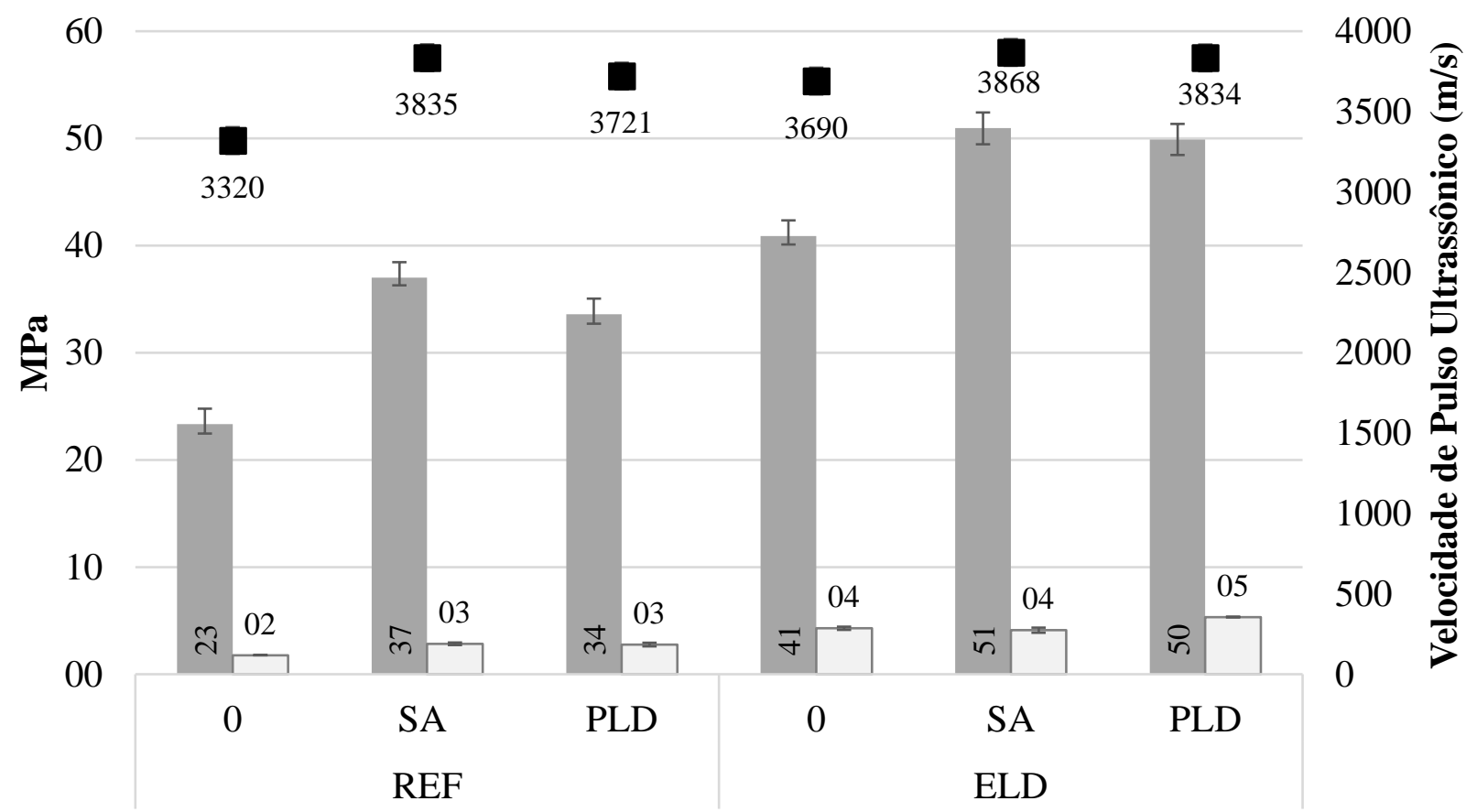

$\square$ Resistência à compressão $\square$ Resistência à tração $\square$ Velocidade de Pulso Ultrassônico

Figura 3 - Caracterização mecânica dos concretos e velocidade de pulso ultrassônico

O VPU estuda principalmente a estrutura de poros do concreto, assim menores velocidades indicam matrizes mais porosas (POPOVICS, ROSE e POPOVICS, 1990). Segundo Saxena et al (2018) e Saint-Pierre et al (2016) todos os concretos, exceto o REF-00, podem ser classificados como de boa qualidade $(3500 \mathrm{~m} / \mathrm{s}<\mathrm{VPU}<4000 \mathrm{~m} / \mathrm{s})$. Esse resultado indica a boa homogeneidade dos concretos produzidos e conversam diretamente com o resultado de absorção de água por imersão.

Com relação a resistência à compressão, observa-se inicialmente que os agregados de escória de aciaria aumentaram cerca de 50\% a resistência a compressão do concreto. Esse resultado corrobora com a literatura, onde Biskri et al (2017), SanJosé et al (2014) e Pellegrino e Gaddo (2009) também observaram melhora nas propriedades mecânicas. Esse resultado está relacionado ao agregados de escória serem mais resistentes, como observados pelo resultado de resistência ao esmagamento, de acordo com a caracterização do material $38 \%$ superior.

Além disso, destaca-se a morfologia cúbica da escória de aciaria e sua superfície rugosa. Essas características permitem o acumúlo de água nas reentrâncias da sua interface permitindo formação de C-S-H e reduzindo a porosidade. Essa teoria é de certa forma comprovada por diversos estudos que observaram diminuição da zona de transição e interface em concretos que utilizam agregado de escória de aciaria como Brand e Roesler (2018), Andrade (2018) e Pang et al (2015). A Figura 4 mostra a superfície dos agregados graúdos. Observe que a escória de aciaria é coberta por cavidades e irregularidades enquanto a gnaisse é lisa.
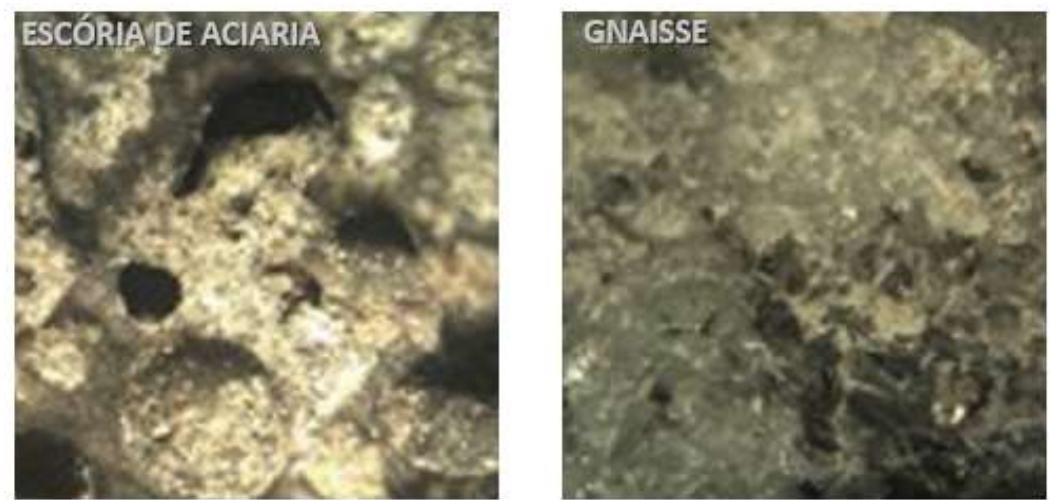

Figura 4 - Superfície dos agregados graúdos utilizados 
Com relação as adições minerais, observa-se que a incorporação de sílica ativa ou powder LD a concretos com agregado convencional aumenta cerca de 50\% a resistência à compressão, para aqueles com agregado de escória de aciaria esse acréscimo é $23 \%$. Comparando o resultado dos concretos sem adição com os de incorporação de powder LD (para ambos os agregados) nota-se uma melhora da resistência à compressão o que pode indicar alguma atividade cimentante ou efeito nucleador. De qualquer forma, esse resultado concorda com a literatura e os resultados de Roslan et al (2016) e Carvalho et al (2019). Os resultados de resistência à tração por compressão diametral conversam com os de compressão, apresentando indíces de correlação com à compressão de 8-10\%.

\section{CONCLUSÃO}

Com base no programa experimental realizado nesse estudos conclui-se que:

- A utilização de agregados de escória de aciaria melhora as propriedades mecânicas da matriz, isso se deve a maior resistência do agregado em si e a sua superfície rugosa.

- Com base no resultado de velocidade de pulso ultrassônico, os concretos com agregado de escória apresentam matrizes semelhantes ao convencional, indicando homogeneidade.

- A incorporação de escória de aciaria como adição mineral não prejudicou as propriedades do concreto, apresentando características semelhantes aquele produzido com adição comercial.

- O powder LD melhorou mecanicamente o concreto quando comparado aqueles sem adição, isso indica um possível efeito nucleador ou até mesmo ação cimentante, devido a semelhança desse resultado com aqueles onde incoporaram sílica ativa.

Assim, com base nesses resultados indica-se a possível viabilidade técnica de utilização de escória de aciaria como agregado e adição mineral.

\section{AGRADECIMENTOS}

O presente trabalho foi realizado com apoio da Coordenação de Aperfeiçoamento de Pessoal de Nível Superior - Brasil (CAPES) - Código de Financiamento 001. Os autores também agradecem à FAPEMIG, CNPq e UFOP pelo apoio para a realização e apresentação dessa pesquisa. Somos gratos ainda pela infraestrutura e colaboração do Grupo de Pesquisa em Resíduos Sólidos - RECICLOS - CNPq. 


\section{REFERÊNCIAS}

ABNT. NBR 9776: Aggregate - Determination of fine aggregate specific gravity by chapman vessel - Method of test. [S.l.]: [s.n.], 1986.

ABNT. NBR NM 46: Agregados - Determinação do material fino que passa através da peneira 75 micrometro, por lavagem. Rio de Janeiro: Associação Brasileira de Normas Técnicas, 2003.

ABNT. NBR 9778: Argamassa e concreto endurecidos - Determinação da absorção de água, índice de vazios e massa específica. Rio de Janeiro: Associação Brasileira de Normas Técnicas, 2005.

ABNT. NBR NM 45: Agregados - Determinação da massa unitária e do volume de vazios. Rio de Janeiro: Associação Brasileira de Normas Técnicas, 2006.

ABNT. NBR 7211: Agregado para concreto - Especificação. Rio de Janeiro: Associação Brasileira de Normas Técnicas, 2009.

ABNT. NBR NM 53: Agregado graúdo - Determinação de massa específica, massa específica aparente e absorção de água. Rio de Janeiro: Associação Brasileira de Normas Técnicas, 2009.

ABNT. NBR 7222: Concreto e argamassa — Determinação da resistência à tração por compressão diametral de corpos de prova cilíndricos. Rio de Janeiro: Associação Brasileira de Normas Técnicas, 2011.

ABNT. NBR 7212: Execução de concreto dosado em central — Procedimento. Rio de Janeiro: Associação Brasileira de Normas Técnicas, 2012.

ABNT. NBR 8802: Concreto endurecido - Determinação da velocidade de propagação de onda ultrassônica. Rio de Janeiro: Associação Brasileira de Normas Técnicas, 2013.

ABNT. NBR 9938: Agregados — Determinação da resistência ao esmagamento de agregados graúdos — Método de ensaio. Rio de Janeiro: Associação Brasileira de Normas Técnicas, 2013.

ABNT. NBR 8953: Concrete for structural use: Density, strength and consistence classification. Rio de Janeiro: [s.n.], 2015.

ABNT. NBR 16665: Cimento Portland - Requisitos. Rio de Janeiro: [s.n.], 2018.

ABNT. NBR 5739: Concreto - Ensaio de compressão de corpos de prova cilíndricos. Rio de Janeiro: Associação Brasileira de Normas Técnicas, 2018.

ABNT. NBR 7809: Agregado graúdo - Determinação do índice de forma pelo método do paquímetro - Método de ensaio. Rio de Janeiro: [s.n.], 2019.

ALEXANDER, M.; MINDNESS, S. Aggregates in Concrete. New York: CRC Press, 2005.

ANDRADE, H. D. Carbonatação em Concretos de Escória de Aciaria. Ouro Preto: Diss. Mestrado, 2018.

ANEPAC. Relatório: O Mercado de agregado no Brasil. São Paulo: Associação Nacional das Entidades de Produtores de Agregados para Construção, 2015.

BISKRI, Y. et al. Mechanical and durability characteristics of High Performance Concrete containing steel slag and crystalized slag as aggregates. Construction and Building Materials, v. 150, p. 167-178, 2017.

BRAND, A.; ROESLER, J. Interfacial transition zone of cement composites with steel furnace slag aggregates. Cement and Concrete Composites, v. 86, p. 117-129, 2018.

CARVALHO, J. M. F. et al. More eco-efficient concrete: an approach on optimization and use of waste-based supplementary cementing materials. Construction and Building Materials, v. 206, p. 397-409, 2019. 
CARVALHO, J. M. F. et al. Enhancing the eco-efficiency of concrete using engineered recycled mineral admixtures and recycled aggregates. Journal of Cleaner Production, 257, 2020. 120530.

DEFÁVERI, K. C. S. et al. Glass Wool Residue: A Potential SupplementaryCementitious Material. ACI Materials Journal, 2019. 43-49.

FONTES, W. C. et al. Mortars for laying and coating produced with iron ore tailings from tailing dams. Construction and Building Materials, 2016. 988-995.

FRANCO , L. C. et al. Design and thermal evaluation of a social housing model conceived with bioclimatic principles and recycled aggregates. Sustainable Cities and Society, 2019.

IABR. Relatório de Sustentabilidade 2016-2017. Rio de Janeiro. 2018.

MEHTA, K.; MONTEIRO, P. Concreto: estrutura, propriedades e materiais. São Paulo: Editora Ibracon, 2013.

MONOSI, S.; RUELLO, M. L.; SANI, D. Electric arc furnace slag as natural aggregate replacement in concrete production. Cement and Concrete Composites, v. 66, p. 66-72, 2016.

PADMALAL, D. et al. Environmental effects of river sand mining: a case from the river catchments of Vembanad lake, Southwest coast of India. Environmental Geology, v. 54, p. 879-889, 2008.

PANG, B.; ZHOU, Z.; XU, H. Utilization of carbonated and granulated steel slag aggregate in concrete. Construction and Building Materials, v. 84, p. 454-467, 2015.

PELLEGRINO, C.; GADDO, V. Mechanical and durability characteristics of concrete containing EAF slag as aggregates. Cement \& Concrete Composites, v. 31, p. 663-671, 2009.

POPOVICS, S.; ROSE, J.; POPOVICS, J. The Behavior of Ultrasonic Pulses in Concrete. Cement and Concrete Research, v. 20, p. 259-270, 1990.

ROSLAN, N. H. et al. Performance of steel slag and steel sludge in concrete. Construction and Building Materials, v. 104, p. 16-24, 2016.

SAINT-PIERRE, F. et al. Concrete Quality Designation based on Ultrasonic Pulse Velocity. Construction and Building Materials, v. 125, p. 1022-1027, 2016.

SAN-JOSÉ, J. T. et al. The performance of steel-making slag concretes in the hardened state. Materials and Design, v. 60, p. 612-619, 2014.

SANT'ANA FILHO, J. N. et al. Technical and Environm ental Feasibility of Inter locking Concrete Pavers with Ion Ore Tailings from tailing damns. Journal of Materials in Civil Engineering, 2017. 04017104.

SAXENA, S.; TEMBHURKAR, A. Impact of use of steel slag as coarse aggregate and wastewater on fresh and hardened properties of concrete. Construction and Building Materials, p. 126-137, 2018.

SHI, Y. et al. Preliminary investigation on the pozzolanic activity of superfine steel slag. Construction and Building Materials, v. 82, p. 227-234, 2017.

SILVA et al. Rock Wool Waste as Supplementary Cementitious Material for Portland Cement-Based Composites. ACI Materials Journal, 2018. 653-661.

SILVA, M. J. et al. Feasibility Study of Steel Slag Aggregates in Precast Concrete Pavers. ACI MATERIALS JOURNAL, v. 113, p. 439-446, 2016.

SOUZA, . B. P. D. ADERÊNCIA DE BARRAS DE AÇO TIPO CA EM CONCRETO SUSTENTÁVEL. Ouro Preto: Dissertação de Mestrado, 2015.

WANG, Q.; YANG, J.; YAN, P. Cementitious properties of super-fine steel slag. Powder Technology, v. 245, p. 35-39, 2013. 